Report No. BMI-1383

UC-25 Metallurgy and Ceramics

(TID-4500, 15th Ed.)

Contract No. W-7405-eng -92

A STUDY OF THE EFFECTS OF FABRICATING

CONDITIONS ON SOME PROPERTIES OF

SINTERED URANIUM MONOCARBIDE

by

Arch B. Tripler, Jr.

M. Jack Snyder

Winston $H_{\text {. Duckworth }}$

October 2, 1959

BATTELLE MEMORIAL INSTITUTE

$505 \mathrm{King}$ Avenue

Columbus 1, Ohio 


\section{DISCLAIMER}

This report was prepared as an account of work sponsored by an agency of the United States Government. Neither the United States Government nor any agency Thereof, nor any of their employees, makes any warranty, express or implied, or assumes any legal liability or responsibility for the accuracy, completeness, or usefulness of any information, apparatus, product, or process disclosed, or represents that its use would not infringe privately owned rights. Reference herein to any specific commercial product, process, or service by trade name, trademark, manufacturer, or otherwise does not necessarily constitute or imply its endorsement, recommendation, or favoring by the United States Government or any agency thereof. The views and opinions of authors expressed herein do not necessarily state or reflect those of the United States Government or any agency thereof. 


\section{DISCLAIMER}

Portions of this document may be illegible in electronic image products. Images are produced from the best available original document. 


\section{TABLE OF CONTENTS}

Page

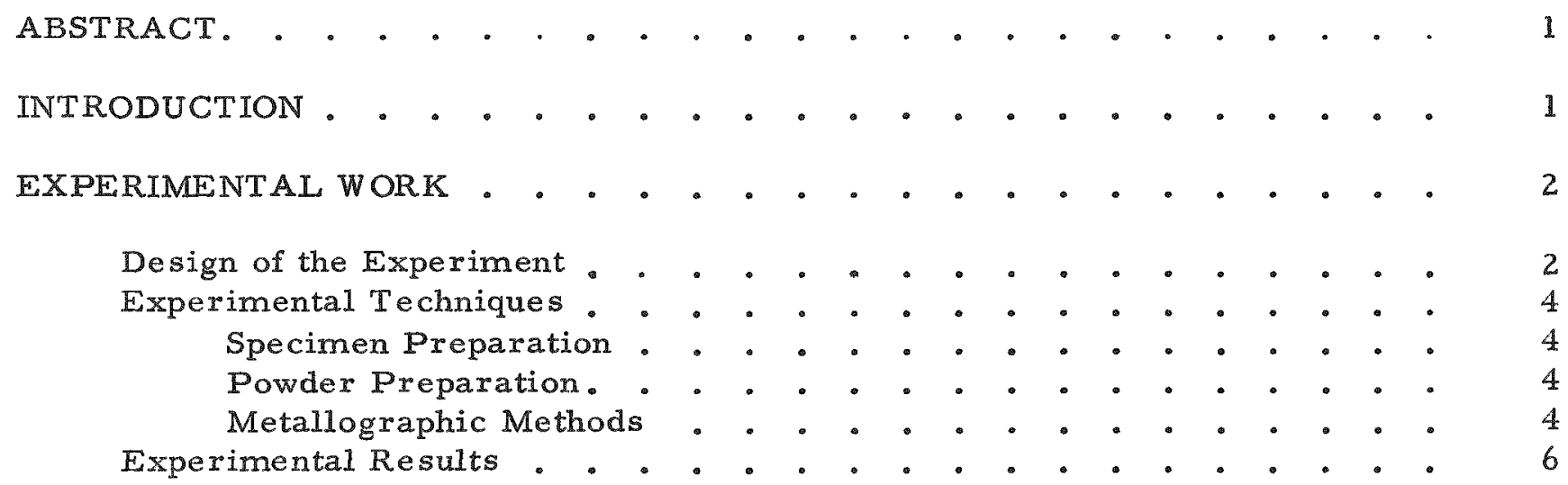

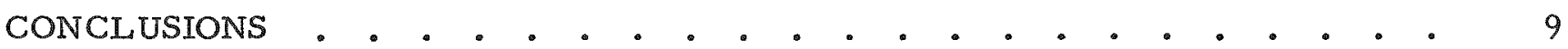

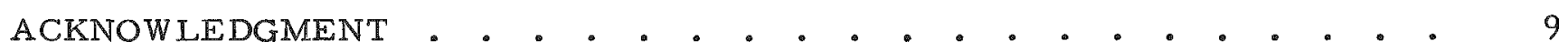

REFERENCES. • • • • . . . . . . . . . . . . . . . . . . . . 9

APPENDIX

EXPERIMENTAL APPARATUS AND METHODS . . . . . . . . . . . A-1 


\title{
A STUDY OF THE EFFECTS OF FABRICATING CONDITIONS ON SOME PROPERTIES OF SINTERED URANIUM MONOCARBIDE
}

\author{
Arch B. Tripler, Jr., M. Jack Snyder, and
}

Winston $\mathrm{H}$. Duckworth

\begin{abstract}
In a supplementary study for the AEC Division of Research, the effect of initial particle size (6.2 and 14.\% $\mu$ ), forming pressure $(50,000$ and $100,000 \mathrm{psi})$, temperature $(1600$ and $1800 \mathrm{C}$ ), and time at temperature ( 1 and $3 \mathrm{hr}$ ) on the bulk density, grain size, and porosity of sintered uranium monocarbide compacts was studied. Apparatus and procedures were described in BMI-1223 and BMI-1313.

Within the limits of the variables studied, there appeared to be no significant changes in these properties of the sintered material attributable to the changes in the fabricating conditions.
\end{abstract}

\section{INTRODUCTION}

The properties of a number of refractory binary compounds of uranium that may have potential application as nuclear fuels are being investigated at Battelle. The results of a literature survey and initial experimental work were reported in BMI-1124(1). Subsequent experimental work was reported in BMI-1223(2) and BMI-1313(3).

This report contains the results of the initial phase of an investigation to deter mine the effects of certain fabrication variables on some of the properties of sintered uranium monocarbide compacts. The work did not include a study of the characteristics of uranium monocarbide powders. Powders produced by different processes or conditions can have widely different behaviors in ceramic processing, and this can also be true of different lots of powder made by the same method if necessary control of processing is not established.

A method for preparing sintered compacts of UC having bulk densities up to 94 per cent of theoretical was developed in the earlier work. (3) The method, in brief, comprised the following steps:

(1) Preparing bulk UC by arc melting

(2) Grinding the arc-melted UC to fine powder (about 5- $\mu$ average particle size)

(3) Placing the powder in a rubber mold and pressing isostatically (in a hydrostatic press) at $100,000 \mathrm{psi}$

(4) Sintering the compact in vacuum for $1 \mathrm{hr}$ at about $1800 \mathrm{C}$.

(1) References at end of text. 
In the work described herein a wider range of fabricating conditions was investigated. The effects of initial particle size, forming pressure, sintering temperature, and time at temperature on bulk density, apparent porosity, and grain size were studied.

\section{EXPERIMENTAL WORK}

\section{Design of the Experiment}

A preliminary series of experiments was conducted to determine whether variations in forming pressure would produce sufficient variation in green (unsintered) density to enable a correlation between forming pressure and sintered density. Individual samples of uranium monocarbide powder having an average particle size of about $6 \mu$ were compacted isostatically at pressures of $20,000,40,000,50,000,80,000$ and $100,000 \mathrm{psi}$. The green densities of the resulting specimens are plotted against forming pressure in Figure 1. There is an approximately linear relationship between forming pressure and bulk density. It was concluded that the difference in green densities resulting from pressures of 50,000 or 100,000 psi might be sufficient to produce a significant difference in the sintered densities.

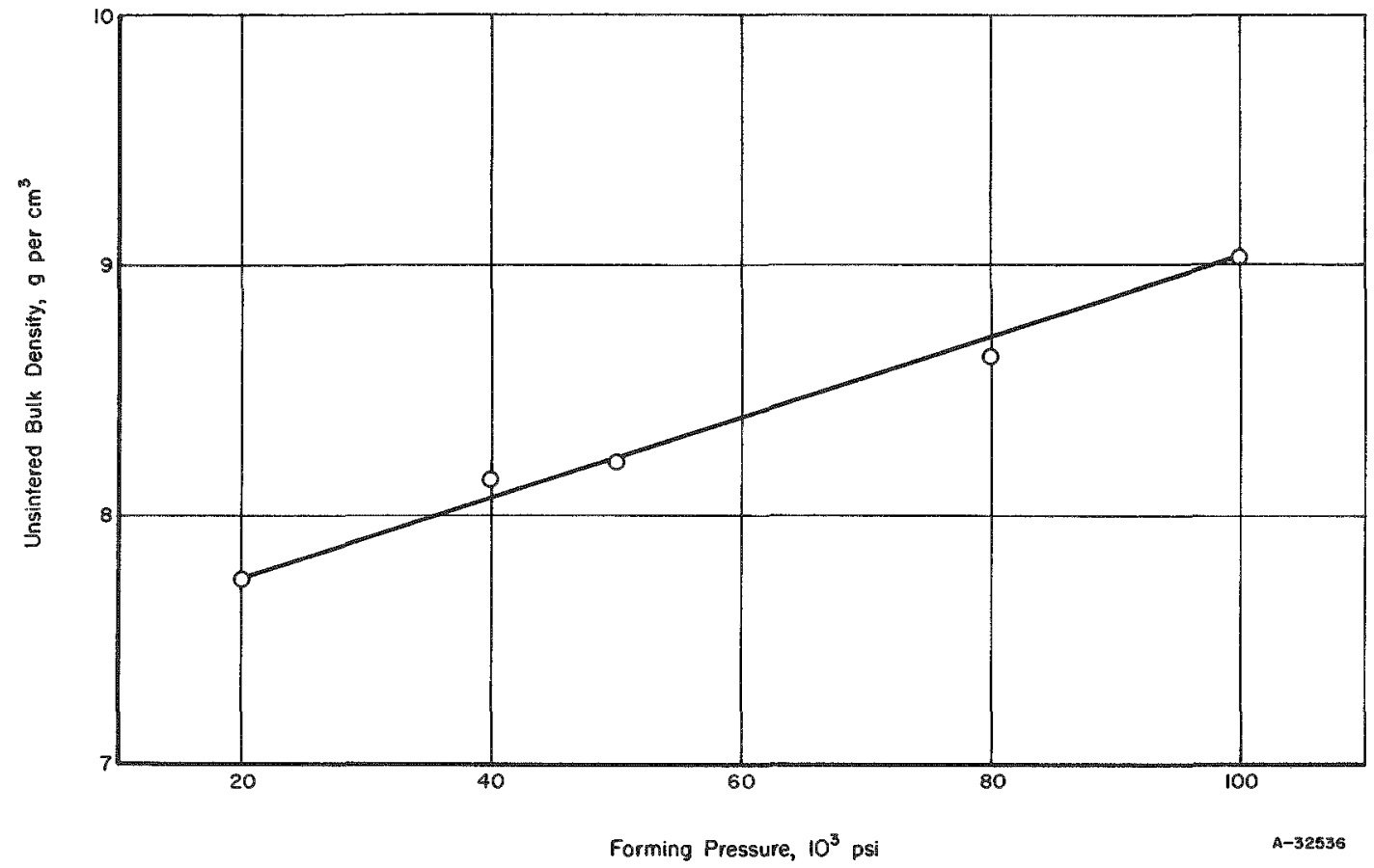

\section{FIGURE 1. EFFECT OF FORMING PRESSURE ON UNSINTERED BULK DENSITY OF URANIUM MONOCARBIDE COMPACTS}

Two levels were then chosen for each of the remaining three fabrication variables. The temperature levels were set at 1600 and $1800 \mathrm{C}$, the time at temperature at $I$ and $3 \mathrm{hr}$, and the initial particle size at approximately 6 and $14 \mu$. Thus, 16 sets of conditions resulted as shown in Table 1. Initially only seven of these conditions were selected for investigation. The remaining nine were to be studied if the initial experimental phase warranted it. 
TABLE 1. FABRICATION CONDITIONS FOR PREPARATION OF SINTERED URANIUM MONOCARBIDE SPECIMENS

\begin{tabular}{|c|c|c|c|c|}
\hline \multirow[b]{2}{*}{ Condition } & \multirow{2}{*}{$\begin{array}{c}\text { Initial } \\
\text { Particle } \\
\text { Size, } \mu\end{array}$} & \multirow{2}{*}{$\begin{array}{c}\text { Forming } \\
\text { Pressure, } \\
10^{3} \mathrm{psi} \\
\end{array}$} & \multicolumn{2}{|c|}{ Sintering Conditions } \\
\hline & & & $\begin{array}{c}\begin{array}{c}\text { Time, } \\
\mathrm{hr}\end{array} \\
\end{array}$ & $\begin{array}{c}\text { Temperature, } \\
\mathrm{C} \\
\end{array}$ \\
\hline 1 & 6.2 & 50 & 1 & 1600 \\
\hline 2 & 14.7 & 50 & 1 & 1600 \\
\hline 3 & 6.2 & 100 & 1 & 1600 \\
\hline 4 & 14.7 & 100 & 1 & 1600 \\
\hline 5 & 6.2 & 50 & 3 & 1600 \\
\hline 6 & 14.7 & 50 & 3 & 1600 \\
\hline 7 & 6.2 & 100 & 3 & 1600 \\
\hline 8 & 14.7 & 100 & 3 & 1600 \\
\hline 9 & 6.2 & 50 & 1 & 1800 \\
\hline 10 & 14.7 & 50 & 1 & 1800 \\
\hline 11 & 6.2 & 100 & 1 & 1800 \\
\hline 12 & 14.7 & 100 & 1 & 1800 \\
\hline 13 & 6.2 & 50 & 3 & 1800 \\
\hline 14 & 14.7 & 50 & 3 & 1800 \\
\hline 15 & 6.2 & 100 & 3 & 1800 \\
\hline 16 & 14.7 & 100 & 3 & 1800 \\
\hline
\end{tabular}


Experimental Techniques

\section{$\underline{\text { Specimen Preparation }}$}

The cylindrical specimens measuring about 1-1/4 in. long by 1/4 in. in diameter were prepared essentially by the four-step procedure given previously with the conditions varied as called for by the experimental design. The use of a wax binder was found to be necessary to obtain sound specimens with the coarse $(14.7 \mu)$ powder when compacting at 50,000 psi. The binder was used in all cases so as not to introduce an additional variable. Details of apparatus and methods are explained or referred to in the Appendix.

\section{Powder Preparation}

The two sizes of UC powder were prepared from the same lot of arc-melted UC. When the average particle size had been reduced to $14.7 \mu$ by ball milling, the powder was divided into two nearly identical batches by mixing and quartering. One batch was then ground further to $6.2-\mu$ average particle size. Both powders were analyzed chemically for uranium and carbon. The results in terms of weight per cent and atomic per cent are given in Table 2. The analyses indicate that the fine powder picked up more contamination than the coarse powder. This would be expected from the longer grinding period.

The particle-size distribution was measured on representative samples by standard petrographic methods. The data are given in Table 3.

\section{Metallographic Methods}

The mounting, grinding, and polishing of the sintered carbide specimens was done by standard techniques. The etchant used is given with the typical photomicrographs shown later.

The percentage of voids was estimated by use of the Hurlbut counter. This apparatus consists of binocular microscope with a motor-driven stage and a manually controlled counting device. As the specimen passes the cross hairs of the microscope, the operator presses one button for voids, a second for carbide particles. The percentage of voids is calculated by dividing the total of the lengths of voids traversed by the total length of the traverse.

The average grain size of carbide grains also was measured with the Hurlbut counter. Here, the average grain size was determined by dividing the total lengths of the grains traversed by the number of grains in the traverse. The average grain sizes also were estimated by comparing the microstructure at 100X with standard ASTM grainsize charts for steel. 
TABLE 2. CHEMICAL ANALYSIS OF URANIUM MONOCARBIDE POWDERS USED FOR FABRICATION OF SINTERED COMPACTS

\begin{tabular}{|c|c|c|c|c|c|}
\hline $\begin{array}{l}\text { Average } \\
\text { Particle } \\
\text { Size, } \mu \\
\end{array}$ & $\begin{array}{c}\text { Uranium, } \\
W / 0\end{array}$ & $\begin{array}{c}\text { Carbon, } \\
W / 0\end{array}$ & $\begin{array}{c}\text { Total } \\
\text { Uranium Plus } \\
\text { Carbon, } \\
w / 0\end{array}$ & $\begin{array}{c}\text { Uranium, } \\
a / 0\end{array}$ & $\begin{array}{c}\text { Carbon, } \\
a / 0\end{array}$ \\
\hline 14.7 & 94.79 & 5.06 & 99.85 & 48.6 & 51.4 \\
\hline 6.2 & 93.66 & 4.96 & 98.62 & 48.8 & 51.2 \\
\hline
\end{tabular}

TABLE 3. PARTICLE SIZE OF URANIUM MONOCARBIDE POWDERS USED FOR FABRICATION OF SINTERED COMPACTS

\begin{tabular}{lccr}
\hline \hline \multirow{2}{*}{$\begin{array}{c}\text { Description } \\
\text { of Powder }\end{array}$} & Minimum & Parlicle Size, $\mu$ & Maximum \\
\hline \multirow{2}{*}{ Fine } & $<0.5$ & 48.2 & Average \\
Coarse & $<0.8$ & 89 & 6.2 \\
\hline
\end{tabular}




\section{Experimental Results}

Table 4 contains the average values for bulk density, percentage of voids, and grain size (both Hurlbut and ASTM) for each of the fabricating conditions investigated.

Referring to Conditions 1 through 4 , in which initial particle size and forming pressure were varied, it can be seen that there is no apparent correlation between the fabricating conditions and bulk density, percentage of voids, or grain size (Hurlbut count). There appears to be a correlation between initial particle size and final grain size as determined by the ASTM method. The Hurlbut count, however, is believed to be the more accurate.

Figures 2 and 3 are photomicrographs showing results of sintering at Conditions 2 and 3, respectively. These two photomicrographs are typical examples of the two principal types of grain structure observed in the specimens prepared by Conditions 1, 2, 3, and 4. In addition to illustrating the types of grain structure, these show how the ASTM method brings to light a factor ignored by the Hurlbut count. According to the Hurlbut count these two specimens have essentially the same average grain size: 9.2 and $9.4 \mu$, respectively. A cursory glance at the pictures makes this seem incredible. More thorough examination shows that the Hurlbut count, which results in a true average, is accurate. The specimen represented by Figure 2 contains many large and many small grains, all differing considerably from the average. Because of the many large grains, casual observation leads to an overestimating of the average grain size. In Figure 3 the grains are more nearly uniform in size and the average size is more readily estimated visually. The difference between the ASTM counts for the two specimens reflects the difference in character of the grain structure not apparent from the mean value obtained by the Hurlbut count.

There appears to be no consistent correlation between the average bulk-density values given in Table 4 and the average void volume. This is because the bulk density was measured on the entire specimen, whereas the void volume was estimated from measurements on only one or two cross sections for each specimen.

Consider next Conditions $3,7,11$, and 15, in which tempereature and time at temperature were varied. Specimens fabricated under the last three of these conditions had a core of finex grained material surrounded by an annular ring of coarser grained material. The coarser grains were surrounded with grain-boundary material that was rich in uranium. Figure 4 is a typical photomicrograph of this type of material. This same phenomenon was observed in earlier work (3) and at that time was believed due to the use of starting material with a deficiency of carbon. In the earlier work uniform specimens were obtained when starting material with a slightly higher carbon content was used.

In the present work the starting material had even a larger excess of carbon and yet the duplex structure appeared again in Conditions 7,11 , and 15. It is now tentatively suggested that the formation of the uranium-rich phase may be due to partial oxidation of the surface carbide even at low pressures to form uranium metal and carbon monoxide.

- The average grain-size values just given are for individual cross sections, parts of which are shown in Figures 2 and 3, and are not to be confused with the values given in Table 4 , which are the average values for two or more cross sections. 
TABLE 4. CONDITIONS OF PREPARATION AND RESULTANT AVERAGE PROPERTIES OF SINTERED URANIUM MONOCARBIDE SPECIMENS

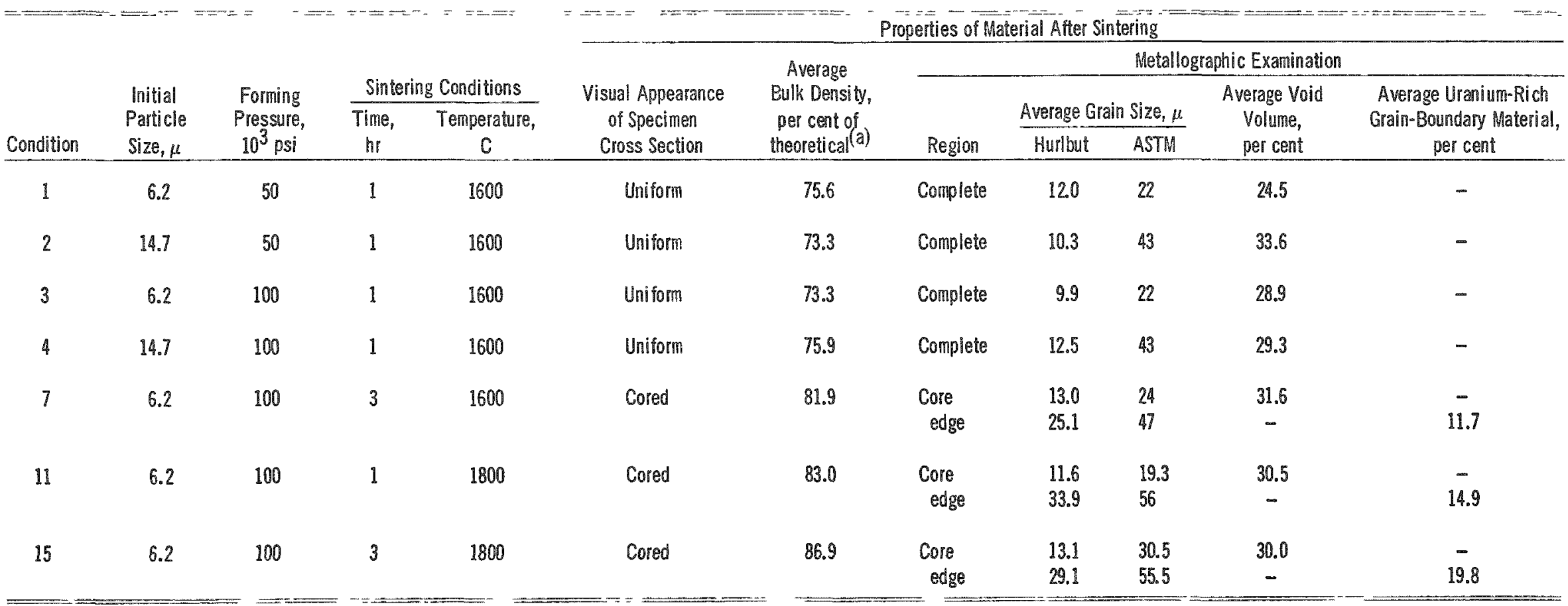

(a) The theoretical bulk density of UC is taken as $13.63 \mathrm{~g} \mathrm{per} \mathrm{cm}^{3}$. 


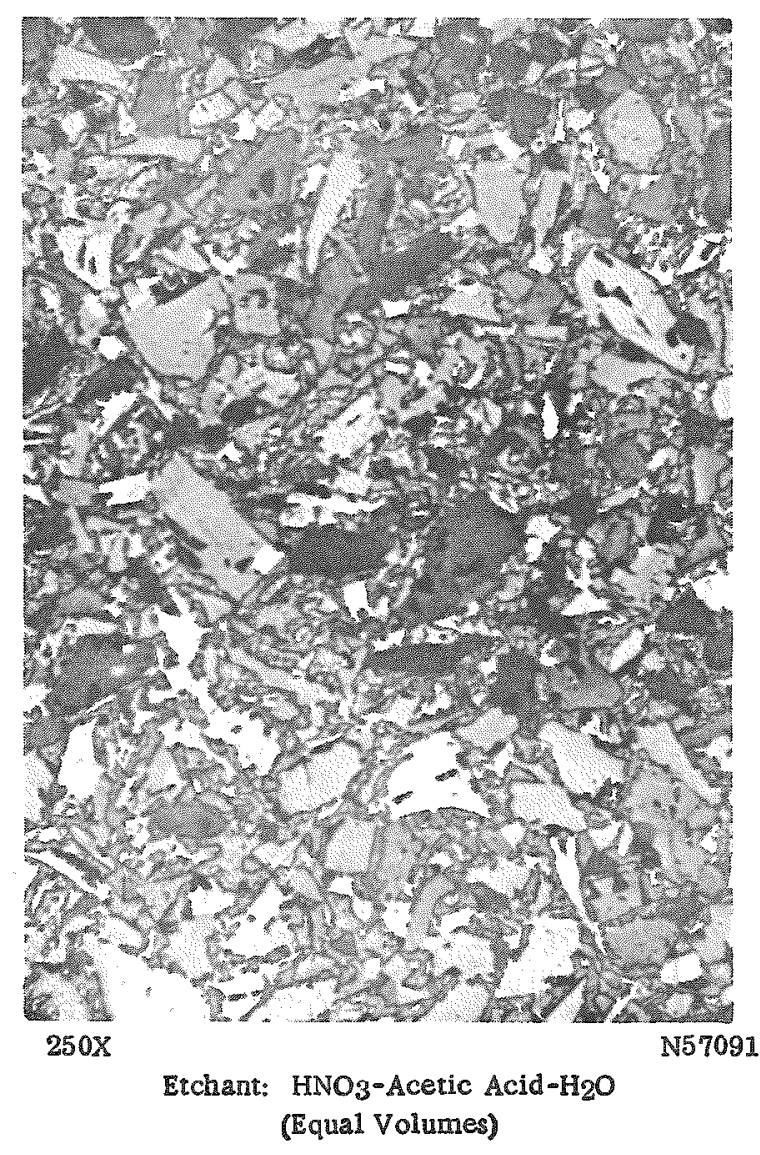

FIGURE 2. MICROSTRUCTURE OF SINTERED UC PREPARED ACCORDING TO CONDITION 2

The material is mostly single phase. The small white areas are believed to be uranium. The dark gray or black areas are voids.

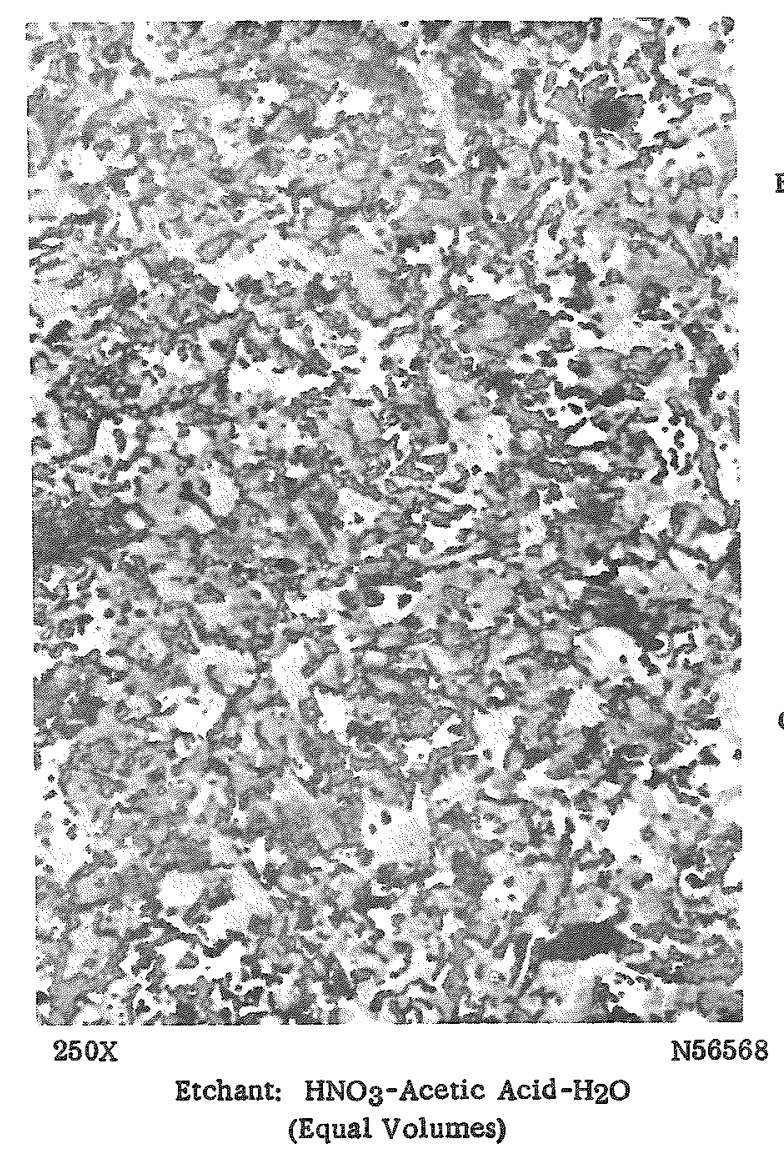

FIGURE 3. MICROSTRUCTURE OF SINTERED UC PREPARED ACCOROING TO CONDITION 3

The material is mostly single phase. The small white areas are believed to be uranium. The dark gray or black areas are voids.

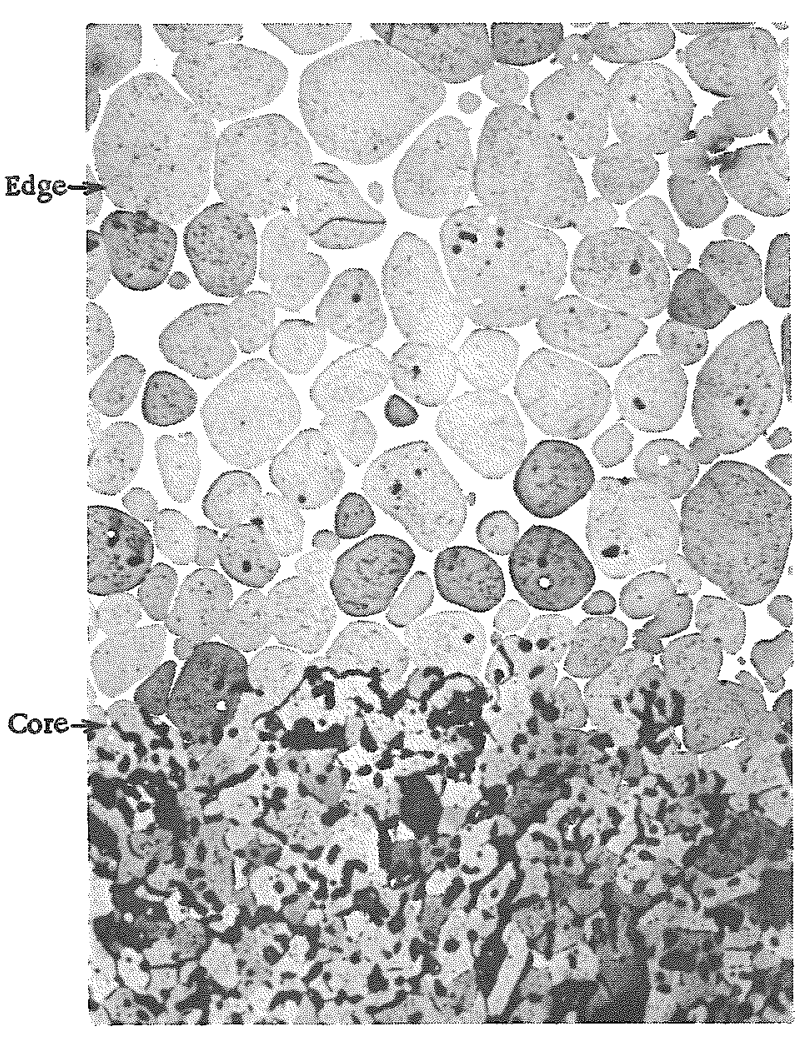

$250 \mathrm{X}$

Etchant: HNO3-Acetic Acid- $\mathrm{H}_{2} \mathrm{O}$ (Equal Volumes)

FIGURE 4. MICROSTRUCTURE OF SINTERED UC PREPARED ACCORDING TO CONDITION 15

Edge (large-grained material) shows UC matrix with uranium-rich grainboundary phase. Core (smallgrained material) is porous. Black areas are voids. 
Although the pumping capacity of the vacuum system was large enough to overcome small air leakage into the furnace and to maintain a low pressure, a small amount of oxygen undoubtedly entered the furnace continually and was available for oxidizing the carbide.

The grain growth observed in the outer portion of some specimens is a function of the dual factors, temperature and time at temperature. The outer ring was larger in area, for example, when produced by Condition $15(1800 \mathrm{C}, 3 \mathrm{hr})$ than when formed by Conditions 7 or $11(1600 \mathrm{C}, 3 \mathrm{hr} ; 1800 \mathrm{C}, 1 \mathrm{hr})$.

Data on both core and edge portions are given for Conditions 7,11 , and 15 in Table 3. Considering first the core data, and including Condition 3, fabrication conditions appear to have little influence on percentage of voids or Hurlbut grain size. There is an upward trend in the case of ASTM grain-size measurements. There is no correlation between the fabricating conditions and the data for the edges except in the case of the percentage of uranium-rich grain-boundary material. The latter increases slowly with increases in the time-temperature factor.

The development of the duplex structure naturally precluded the formation of the uniform, high-density type of material achieved previously.

\section{CONCLUSIONS}

With the exception of the duplex edge-core effect, no significant changes were observed in the sintered compacts as a result of changes in fabricating conditions. It is concluded that, within the limits studied, initial particle size $(6.2$ and $14.7 \mu)$ and forming pressure $(50,000$ and 100,000 psi) have little or no effect and that temperature (1600 and $1800 \mathrm{C})$ and/or time at temperature ( 1 and $3 \mathrm{hr}$ ) have only a slight effect on the final properties.

\section{ACKNOWLEDGMENT}

The authors acknowledge the work of Arnold F. Gerds of the Battelle staff in preparing and analyzing the metallographic specimens.

\section{REFERENCES}

(1) Loch, L. D., Engle, G. B., Snyder, M. J., and Duckworth, W. H., "Survey of Refractory Uranium Compounds", BMI-1124 (August 7, 1956).

(2) Snyder, M. J., and Duckworth, W. H., "Properties of Some Refractory Uranium Compounds", BMI-1223 (September 9, 1957). 
(3) Tripler, Arch B., Jr., Snyder, M.J., and Duckworth, W. H., "Further Studies of Sintered Refractory Uranium Compounds", BMI-1313 (January 27, 1959).

(4) Wagner, H. E., and Harman, C. G., "Hydrostatic Pressing as a Fabrication Technique", Am. Ceram. Soc.Bull., 30, 341 (1951). 


\section{APPENDIX}

EXPERIMENTAL APPARAT US AND METHODS 


\section{APPENDIX}

\section{EXPERIMENTAL APPARATUS AND METHODS}

Arc Melting

A description of the arc-melting furnace and operating techniques are given on pages 2 and 3 of BMI-1223.(2)

Crushing and Grinding

The arc-melted UC was first crushed to minus 10 -mesh size in a diamond mortar. This preliminary crushing was done in a glove box which contained dried and purified argon. The crushed material was then transferred from the glove box in a closed argoncontaining can to a rubbex-lined ball-mill jar. The ball mill contained uranium rods and $\mathrm{cp}$ acetone. The latter acted to minimize oxidation of the UC during grinding. The grinding continued for 2 to $8 \mathrm{hr}$, depending on the final size desired. The carbide picked up some contamination from the filler material in the rubber, but not so much as when Alundum balls and unlined jars were used.

When the grinding was completed the entire contents of the jar were dumped on a 10-mesh sieve and the acetone and UC passed through to the pan beneath. The UC settled rapidly and most of the acetone was then siphoned off. The pan containing the moist UC was placed in the transfer lock of the glove box, and a rapid stream of argon was passed through the lock for $15 \mathrm{~min}$. After reducing the argon flow to the normal rate, the UC was allowed to dry overnight.

Particle-Size Determination

The average particle size was determined by petrographic techniques.

Isostatic (Hydrostatic) Pressing

All specimens were isostatically pressed in a hydrostatic press at pressures up to 100,000 psi. (4) The powders were placed in the rubber molds in an axgon atmosphere.

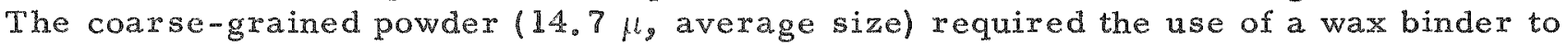
obtain sound specimens when pressed at 50,000 psi. So as not to introduce an additional variable, all specimens were compacted using powder to which had been added $1 \mathrm{ml}$ of 3 w/o Carbowax in $\mathrm{CCl}_{4}$ for each $5 \mathrm{~g}$ of $\mathrm{UC}$.

\section{Vacuum Furnace}

The graphite resistance-type vacuum furnace used to sinter the compacts was described in BMI-1223. (2) The starting vacuum was $2 \times 10^{-5} \mathrm{~mm}$ of mercury. The rate of increase of temperature was kept as constant as possible. During the early part of the heating-up period the pressure rose as the binder vaporized from the specimen. In 
order to keep the pressure from exceeding $200 \mu$ (to avoid cracking the diffusion-pump oil), the temperature had to be raised carefully over the critical range. For some specimens it took longer than for others, but the heating rates were approximately the same, averaging about $500 \mathrm{~F}$ per $\mathrm{hr}$. 